\title{
Bioconcreto: Uma revisão de sua aplicação na construção civil
}

\author{
Bioconcrete: A review of its application in civil construction \\ Bioconcreto: Una revisión de su aplicación en la construcción civil
}

Recebido: 25/03/2021 | Revisado: 31/03/2021 | Aceito: 04/04/2021 | Publicado: 14/04/2021

\author{
Aurilaine Ávila de Freitas \\ ORCID: https://orcid.org/0000-0003-1882-473X \\ Universidade do Estado de Minas Gerais, Brasil \\ E-mail: aurilainefreitas@yahoo.com.br \\ Ediene Monteiro Romão \\ ORCID: https://orcid.org/0000-0002-3413-0423 \\ Universidade do Estado de Minas Gerais, Brasil \\ E-mail: edienemr@hotmail.com \\ Sabrina de Oliveira Anício \\ ORCID: https://orcid.org/0000-0001-5438-1388 \\ Universidade de São Paulo, Brasil \\ E-mail: sabrinadeoliveira@usp.br \\ Adriano José de Barros \\ ORCID: https://orcid.org/0000-0003-4199-4999 \\ Pontifícia Universidade Católica de Minas Gerais, Brasil \\ E-mail: adrianojosebarros@yahoo.com.br
}

\begin{abstract}
Resumo
O concreto é um dos materiais compostos mais consumidos no mundo, perdendo apenas para a água, devido à sua importância na construção civil. De maneira geral, o concreto consiste basicamente em uma mistura de cimento, água e agregados (graúdos e miúdos). Atualmente, outras variações de concretos especiais já estão sendo utilizados, sendo formados por, além da mistura citada, materiais classificados como aditivos, que tem como objetivo principal melhorar as propriedades e características do concreto. Nesse sentido, a preocupação com a qualidade desse material o torna alvo de estudos, cada vez mais avançados, visando buscar o seu melhor desempenho e durabilidade estrutural. Diante disso o presente artigo faz uma revisão bibliográfica sobre a utilização do bioconcreto na construção civil. Tem como objetivo introduzir o conceito do bioconcreto como uma alternativa tecnológica sustentável, que permite prover o auto-reparo de problemas patológicos, como a minimização de fissuras presentes em estruturas de concreto. A pesquisa foi desenvolvida a partir de uma revisão bibliográfica a respeito do tema, passando então por uma abordagem geral, apresentando a origem, dados estatísticos, aplicabilidade e características tecnológicas sobre a temática. Conclui-se com ênfase a importância de se estudar métodos eficientes para promover e melhorar a capacidade de auto cura do concreto, além de potencializar principalmente a utilização de materiais mais sustentáveis no setor da construção civil.
\end{abstract}

Palavras-chave: Bioconcreto; Construção civil; Sustentabilidade.

\begin{abstract}
Concrete is one of the most consumed materials in the world, second only to water, due to its importance in civil construction. In general, concrete basically consists of a mixture of cement, water and aggregates (coarse and fine). Currently, other special concretes are already being used, formed by, besides the mentioned mixture, materials classified as additives, which aims to enhance properties and characteristics of the concrete. In this sense, the concern with the quality of this material makes it the object of advanced studies, aiming at seeking its best performance and structural durability. In view of this, this article presents a bibliographic review on the use of bioconcrete in civil construction. It aims to introduce the concept of bioconcrete as a sustainable technological alternative, which allows providing self-repair of pathological problems, such as minimizing cracks present in concrete structures. The research was developed from a bibliographic review on the subject, passing through a general approach, presenting the origin, statistical data, applicability and technological characteristics about the theme. It is concluded with emphasis the importance of studying efficient methods to promote and improve the self-curing capacity of concrete, besides increasing the use of more sustainable materials in civil construction sector.
\end{abstract}

Keywords: Bioconcrete; Construction; Sustainability.

\section{Resumen}

El hormigón es uno de los materiales compuestos más consumidos en el mundo, solo superado por el agua, debido a su importancia en la construcción civil. En general, el hormigón consiste básicamente en una mezcla de cemento, agua y áridos (gruesos y finos). Actualmente, ya se están utilizando otras variaciones de hormigones especiales, estando formados, además de la mezcla antes mencionada, materiales clasificados como aditivos, cuyo principal 
objetivo es mejorar las propiedades y características del hormigón. En este sentido, la preocupación por la calidad de este material lo convierte en objeto de estudios, cada vez más avanzados, con el objetivo de buscar sus mejores prestaciones y durabilidad estructural. Ante esto, este artículo realiza una revisión bibliográfica sobre el uso del biohormigón en la construcción civil. Se pretende introducir el concepto de biohormigón como una alternativa tecnológica sostenible, que permite proporcionar la autorreparación de problemas patológicos, como minimizar las fisuras presentes en las estructuras de hormigón. La investigación se desarrolló a partir de una revisión bibliográfica sobre el tema, pasando luego por un enfoque general, presentando el origen, datos estadísticos, aplicabilidad y características tecnológicas sobre el tema. Se concluye con énfasis en la importancia de estudiar métodos eficientes para promover y mejorar la capacidad de autocurado del hormigón, además de maximizar el uso de materiales más sostenibles en el sector de la construcción civil.

Palabras clave: Bioconcreto; Construcción civil; Sustentabilidad.

\section{Introdução}

Analisando a construção civil e a sociedade ao longo dos anos, descobriu-se que o concreto armado é um material que vem sendo utilizado desde o século XIX e, está presente nos mais diversos tipos de construções (Helene \& Andrade, 2010). Segundo Henriques (2011), o concreto de cimento Portland é um material diversificado e com propriedades altamente desejáveis aos profissionais da área da construção civil. Por determinado tempo, esse material foi considerado eterno, sendo essa afirmação desconsiderada após as estruturas feitas com concreto armado apresentarem falhas.

Geralemente, o concreto é um material extremamente resistente e, quando construídas corretamente e nas condições certas, as estruturas de concreto podem facilmente durar de 50 a 100 anos ou mais. Apesar disso, diversas manifestações patológicas podem atingir tais estruturas, sendo uma delas a inevitável fissuração.

Embora alguns profissionais da área da engenharia civil afirmem que as fissuras de pequena extensão não sejam, geralmente, prejudiciais à integridade estrutural do concreto, elas podem facilitar a entrada de água e agentes agressores no interior da estrutura, afetando consideravelmente a durabilidade do material, por meio de efeitos como a corrosão da armadura (Souza \& Ripper, 1998). Na área da construção civil, a questão de buscar soluções para solucionar os problemas advindos da corrosão tem sido e ainda é debatido de forma constante.

Neste contexto, em virtude da necessidade de se ter estruturas com alta resistência, consequentemente mais sustentáveis e com a finalidade de reduzir os custos de manutenção empregados na construção civil o presente estudo objetiva realizar uma revisão da literatura sobre o emprego do bioconcreto, também denominado como "concreto auto curável" na construção civil.

\section{Metodologia}

Do ponto de vista metodológico, a pesquisa se destaca como exploratória e descritiva. Ela foi determinada por meio de levantamentos de pesquisas bibliográficas que, segundo Gil (2008), visam estudar um fenômeno que se deseja melhor compreender a fim de familiarizar-se com a problemática, construindo um maior número de hipóteses. Por tanto, a pesquisa é descritiva, pois visa à descrição de características de certo grupo ou fenômeno. O embasamento teórico se pautou em dados e informações científicas levantadas em livros e artigos disponíveis na área de exploração.

Após o levantamento das informações buscou-se fazer uma análise detalhada do objeto em estudo. Os resultados foram apresentados de modo quali-quantitativo, abordados dessa forma porque são dados mais exatos e mais usados para estudo do bioconcreto, sendo feito por meio de análises e descrições da complexibilidade do tema proposto.

A pesquisa também se caracteriza como comparativa que, segundo Schneider \& Schmitt (1998), tem como objetivo descobrir regularidades, entender deslocamentos e mudanças, arquitetar modelos e tipologias, identificando continuidades e descontinuidades, semelhanças e diferenças, e explicitando as determinações gerais que regem os fenômenos sociais. 


\section{Resultados e Discussão}

\subsection{Agregados}

De acordo com Pinheiro et al.., (2007), os agregados são partículas minerais que, à medida que são misturadas à massa do cimento, aumentam seu volume reduzindo assim o seu custo, uma vez que geralmente esses materiais são mais baratos. Como agregados, encontram-se areia, pedras e brita.

Segundo a ABNT NBR 7211 (2005), o agregado graúdo é o agregado cujos grãos passam pela peneira com abertura de malha de $75 \mathrm{~mm}$ e ficam armazenados na peneira de abertura de $4,75 \mathrm{~mm}$, de acordo com ensaio efetivado segundo a ABNT NBR NM 248 (2003). Já o agregado miúdo é o agregado cujos grãos passam pela peneira com abertura de 4,75mm e fica retido na peneira com abertura de malha de $150 \mu \mathrm{m}$.

\subsection{Aglomerantes}

Os aglomerantes são componentes cuja função é ligar os outros materiais adicionados à massa, sendo o cimento o mais usualmente utilizado (Pinheiro et al., 2007). Segundo Cincotto (2011), o cimento Portland comum é um produto composto de clínquer e sulfato de cálcio, enquanto os cimentos Portland compostos recebem a adição ou troca do clínquer por filer calcário, materiais pozolânicos e escória de alto forno. O objetivo do cimento ao se combinar com a água é aglomerar partículas e realizar sua ligação pela formação de produtos hidratados com aumento de resistência mecânica.

\section{3 Água}

A água é usada para propiciar a mistura dos outros componentes, além de participar de reações químicas juntamente com o cimento, o que ocasiona o endurecimento do concreto. A composição química nas pastas de cimento em hidratação varia com a relação água/cimento $(\mathrm{a} / \mathrm{c})$, a temperatura e a idade da hidratação e é comum referir-se a esses hidratos simplesmente como C-S-H (Mehta \& Monteiro, 2008).

Esses mesmos autores afirmam que as duas fases do concreto, naturalmente caracterizadas, são a composta pelas partículas de agregado com formas e tamanhos variados e o meio ligante composto de uma massa de pasta de cimento hidratada (Mehta \& Monteiro, 2008).

O procedimento de hidratação da pasta de cimento exerce grande importância na compreensão das propriedades e comportamento do material.

O tipo, a quantidade, o tamanho, a forma e a distribuição das fases presentes em um sólido constituem a sua microestrutura. Os elementos macroscópicos de um material podem ser vistos facilmente em uma seção transversal. [...] O progresso no campo dos materiais resultou principalmente no reconhecimento do princípio de que as propriedades têm origem na microestrutura interna (Mehta \& Monteiro, 2008).

Por esse motivo, o concreto é considerado bifásico em um nível macroscópico, o que pode ser conferido na Figura 1 abaixo. 
Figura 1 - Seção polida de um corpo de prova de concreto.

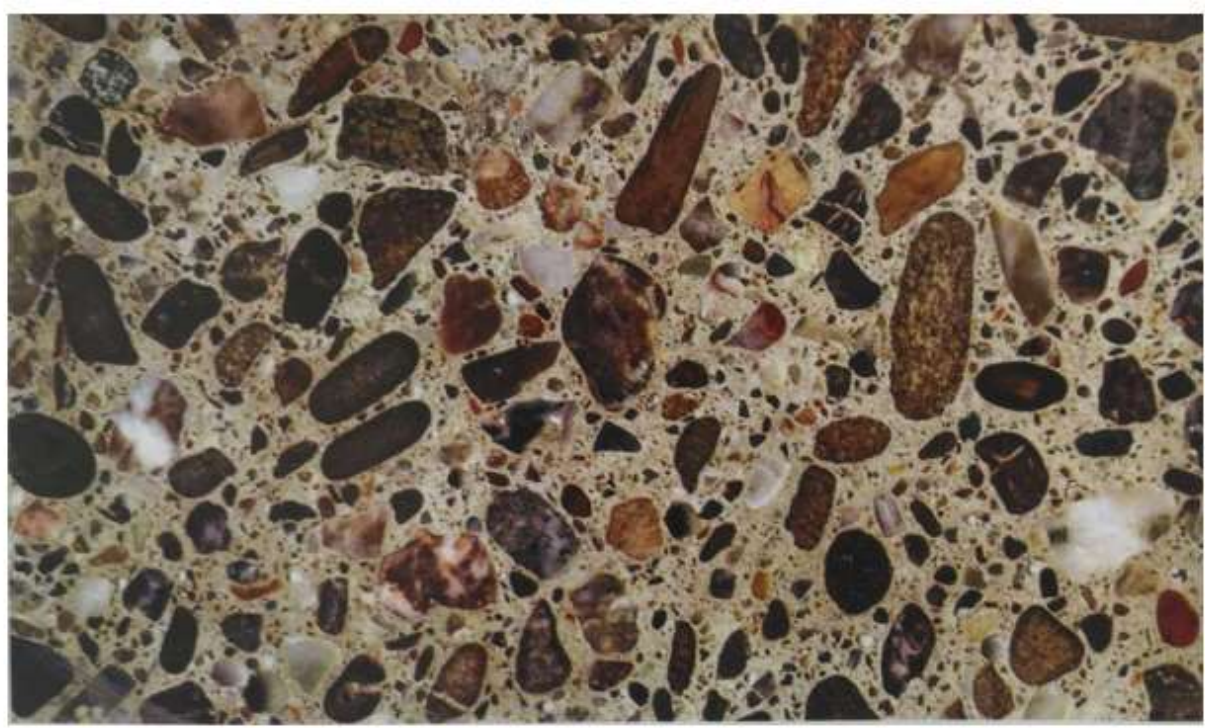

Fonte: Mehta e Monteiro (2008).

As proporções desses componentes adicionadas à massa, o modo de preparo dessa, a qualidade dos componentes adicionados e os fatores externos (temperatura, produtos químicos, grandes tensões, dentre outros), podem favorecer a formação de patologias no concreto.

\section{Fissuras}

A fissuração do concreto é uma das manifestações patológicas mais frequentes na construção civil. Esse tipo de dano pode ser identificado por uma abertura sobre a superfície do concreto, tornando-o uma porta de entrada para agentes agressivos, tanto químicos quanto físicos. Essas manifestações patológicas podem acontecer devido à ocorrência de tensões de tração acima da capacidade resistente do concreto. Elas podem ocorrer tanto no estado fresco quanto no estado endurecido do concreto e sua configuração, posição na peça e variação de abertura permitem, em muitos casos, diagnosticar a causa da sua ocorrência (Gonçalves, 2015; Azevedo, 2011; Trindade, 2015).

As fissuras podem ocorrer em diversos elementos estruturais, tais como vigas, pilares, lajes e outros elementos da construção. As causas variam e, na maioria das vezes, podem ter relação com as tensões dos materiais, que quando solicitados a uma aplicação maior que a resistente sofre uma abertura, classificada de acordo com sua espessura. Tais fissuras podem ocorrer por outras causas, tais como retração plástica térmica ou devido às reações químicas internas do concreto nas primeiras idades. Dessa forma, as fissuras maiores recebem nomenclaturas diferentes, denominadas, por exemplo, como trinca, rachadura, fenda ou brecha (Oliveira, 2012). A Tabela 1 abaixo demonstra a classificação das fissuras conforme sua abertura. 
Tabela 1 - Classificação das fissuras conforme a abertura.

\begin{tabular}{cc}
\hline Tipo de Lesão & Abertura \\
\hline Fissura & até $0,5 \mathrm{~mm}$ \\
\hline Trinca & de $0,5 \mathrm{~mm}$ a $1,5 \mathrm{~mm}$ \\
\hline Rachadura & de $1,5 \mathrm{~mm}$ a $5,0 \mathrm{~mm}$ \\
\hline Fenda & de $5,0 \mathrm{~mm}$ a $10,0 \mathrm{~mm}$ \\
\hline Brecha & acima de $10,0 \mathrm{~mm}$ \\
\hline
\end{tabular}

Fonte: Oliveira (2012).

O tipo de manifestação desenvolvido pelo concreto depende do tipo de condição a que esse é submetido, seja essa intrínseca ou extrínseca a ele. Dessa forma, torna-se complexo o cuidado com o aparecimento desses danos, uma vez que existem diversos tipos de manifestações estruturais e sua formação não depende apenas de fatores internos do concreto, mas também de fatores externos, medidos pelo ambiente (Marcelli, 2007; Trindade, 2015).

O CaCO3 microbiano é considerado um material ecológico e econômico, com um potencial promissor para uma ampla gama de aplicações na engenharia, como consolidação e proteção de superfícies de concreto e pedra, reparo de defeitos e falhas (rachaduras), cimentação ou consolidação de partículas soltas (Medeiros, 2020).

Diante disso, é necessária a busca por alternativas de remediação dessas manifestações, de maneira eficiente e economicamente viável, uma vez que reparos em concreto demandam tempo e mão de obra, originando assim muitos gastos com manutenção. Nesse contexto, uma alternativa bastante interessante é a utilização do bioconcreto em substituição ao uso do concreto comum.

\section{Concreto Comum}

De maneira objetiva, o concreto comum é composto por agregados, aglomerantes e água, sendo considerado o bloco construtor da civilização. Cada um desses componentes deve ser adicionado nas devidas proporções, pois a quantidade de cada parte modifica as características finais do concreto (Pinheiro et al., 2007).

De acordo com Soares et al (2015), a origem do concreto remonta ao tempo pré-histórico, quando o homem abandonou a caverna e foi em busca de novas formas de abrigo. Dessa forma, passou a utilizar estruturas de pedras para preencher seus espaços, além de materiais como lama e argila, conseguindo assim proteção do vento e do frio. Surgiu nesta época a ideia de usar agregados com substâncias mais resistentes de forma a promover maior dureza à mistura. Acredita-se ainda que a mistura cimentícea já tivesse sido notada pelo homem pré-histórico, quando percebeu que as pedras próximas às fogueiras soltavam um pó que endurecia com a ação da umidade do ar.

Conforme o site Cimento.org (2021), o mercado do cimento no Brasil é atualmente composto por 24 grupos cimenteiros, nacionais e estrangeiros, com 100 plantas que produziam clinquer e/ou cimento normalmente até o ano de 2014, quando, no ano seguinte, começou a grande crise do setor e muitas fábricas começaram a fechar unidades de moagem e mesmo plantas integradas. Até o final de 2018 foram fechadas 20 fábricas de cimento, sendo 12 integradas e oito moagens. Das 13 plantas que rodavam e produziam cimento no Estado de São Paulo, seis tiveram as atividades interrompidas.

Conforme dados coletados do Sindicato Nacional da Indústria do Cimento SNIC (2021), na Figura 1, nota-se que o consumo aparente de cimento está com maiores concentrações nas regiões sudeste e sul do Brasil, sendo esse indicador referente ao total da sua produção adicionada das importações e subtraída das exportações. 
Figura 2 - Consumo aparente de cimento no Brasil.

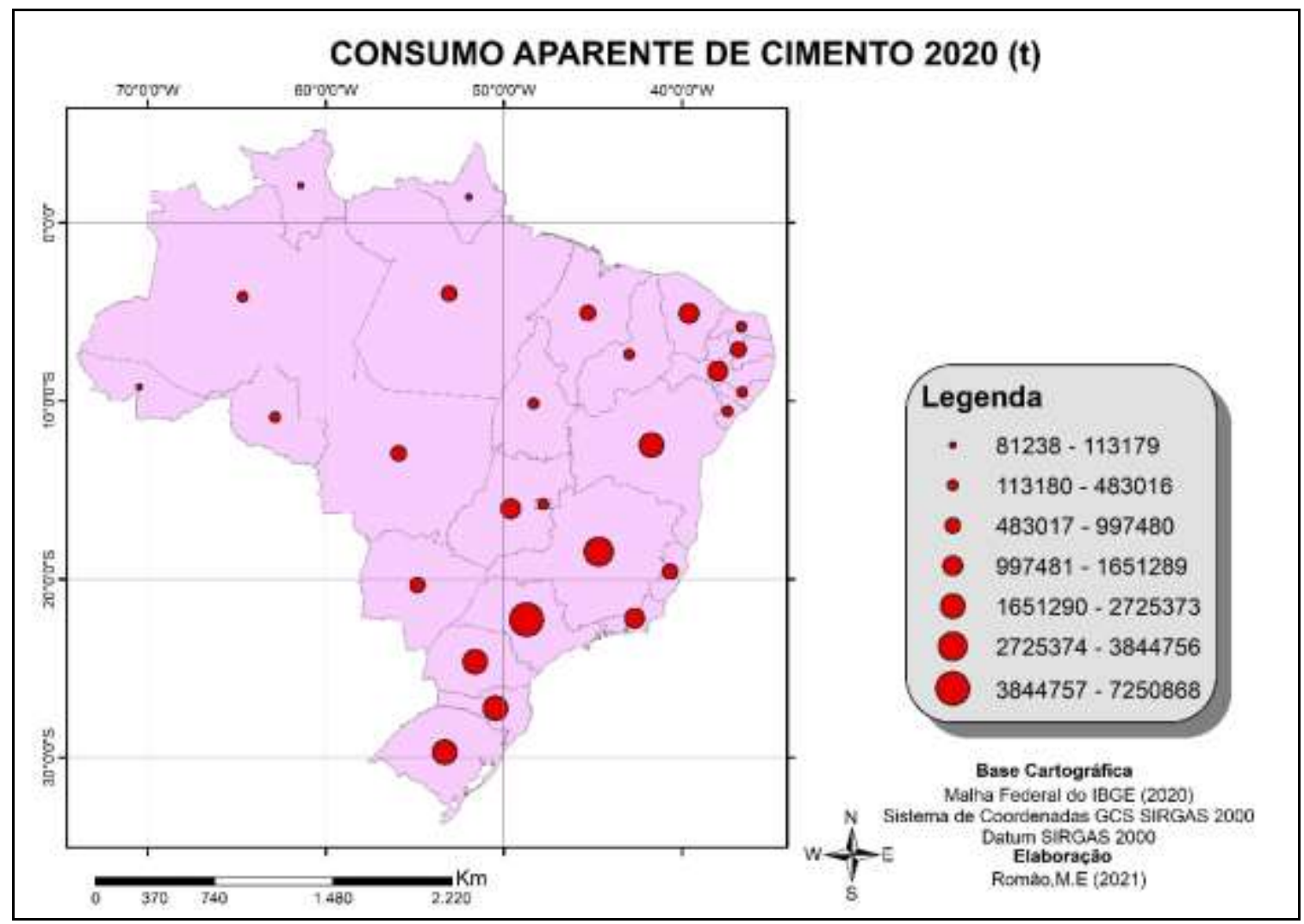

Fonte: IBGE e SNIC, adaptado por Romão (2021).

\section{Bioconcreto}

Conforme Brito et al. (2018), o bioconcreto é uma mistura do concreto tradicional, bactérias e Lactato de cálcio (alimento das bactérias), uma vez que, a bactéria é ativada quando entra em contato com a água ou oxigênio. Se o concreto começa a se degradar, os Bacillus Pseudofirmus se abrem e por meio de reações químicas, as bactérias auxiliam na regeneração do concreto.

Segundo a Thorus Engenharia (2019), o bioconcreto denominado como "concreto auto-curável”, consiste na mistura do concreto com bactérias produtoras de calcário. A mesma diz que, esse concreto autorregenerante é composto pelos mesmos componentes do concreto convencional, mais um elemento adicional denominado agente de cura, que por sua vez é composto por bactérias Bacillus Pseudofirmu e lactato de cálcio $\left(\mathrm{C}_{6} \mathrm{H}_{10} \mathrm{CaO}_{6}\right)$. A Figura 3 apresenta a disposição desses esporos bacterianos. 
Figura 3 - Fotografia de esporos bacterianos por microscopia eletrônica.

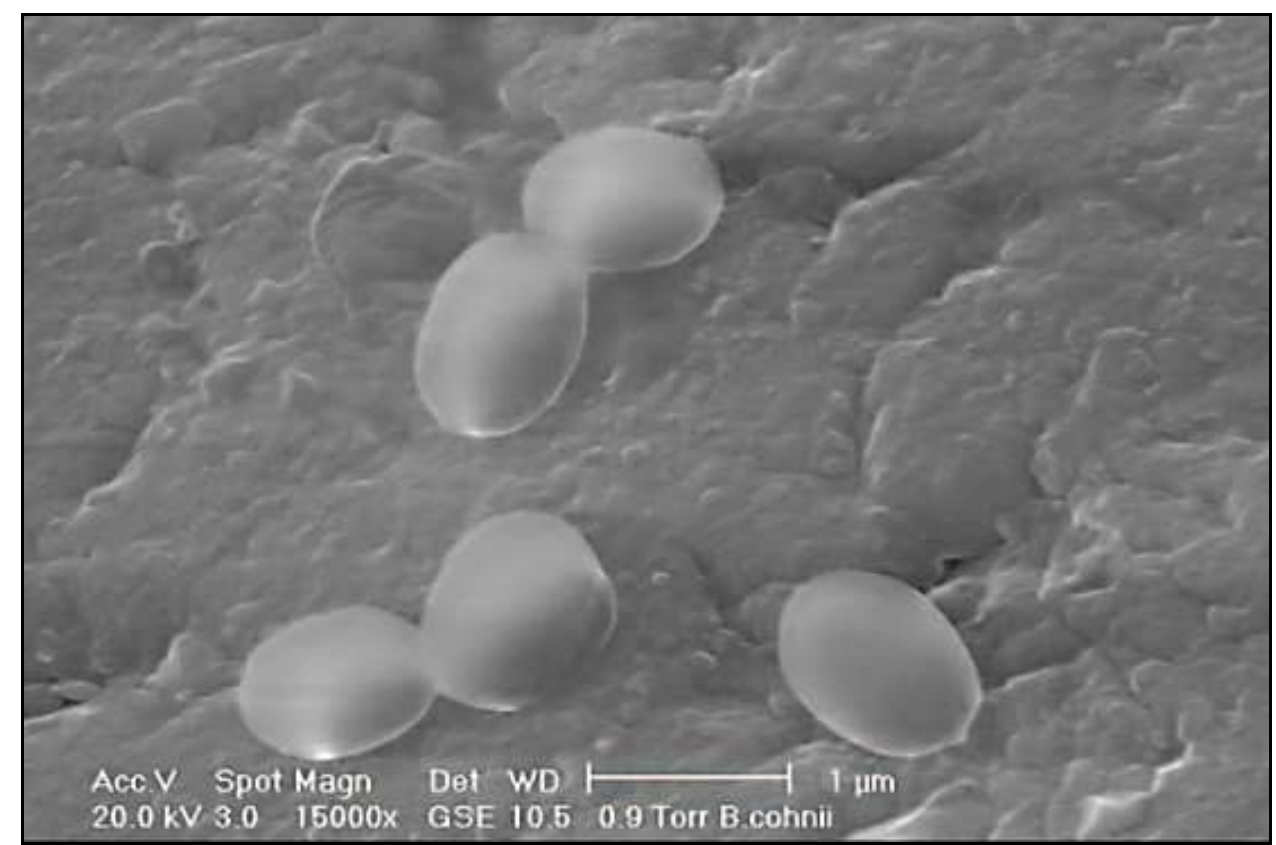

Fonte: Arnold (2011).

O processo de auto-cicatrização do concreto se dá a partir do momento em que essas bactérias inativas presentes no concreto são ativadas ao entrarem em contato com a água, que entra nas fissuras formadas. Essas fissuras são, então, rapidamente preenchidas e seladas por meio da precipitação de carbonato de cálcio $\left(\mathrm{CaCO}_{3}\right)$, produzido pelo aumento do número de bactérias, mediada metabolicamente pelos micro-organismos presentes no concreto, como é possível ver na Figura 4.

Figura 4 - Esquema de autocicatrização em bioconcreto.

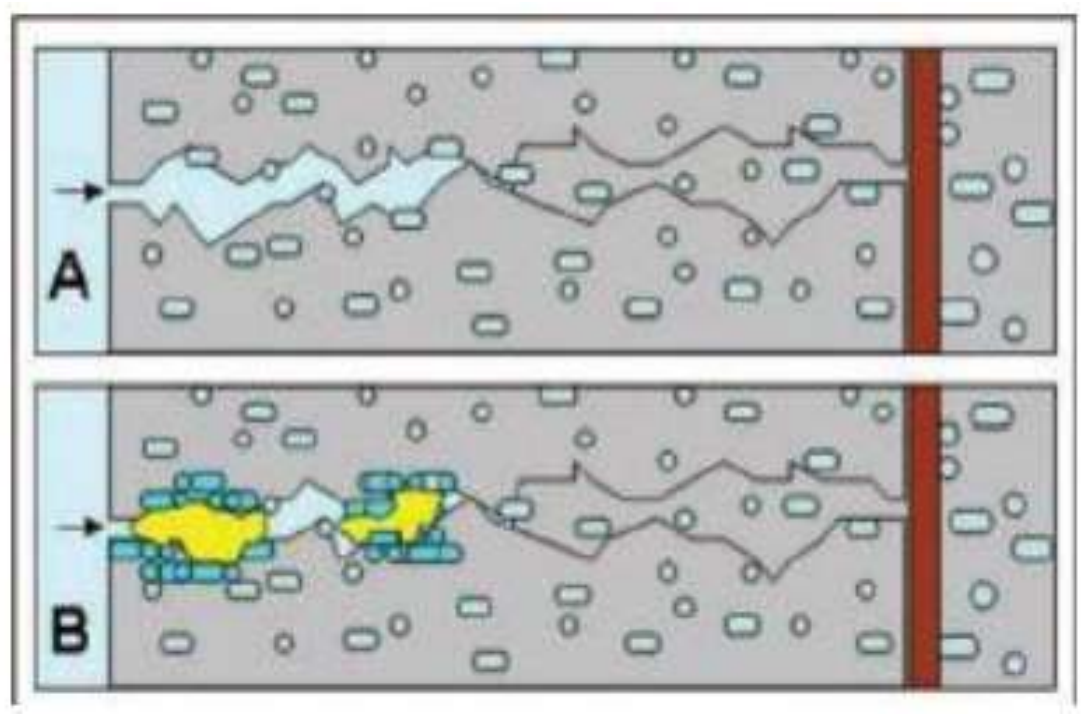

Fonte: Arnold (2011)

Ainda sobre esse processo, Oliveira (2015) e Takagi (2013) em seus estudos afirmam que quando o concreto é fissurado, as bactérias produzem calcário e reestruturam a falha formada. Para manter as bactérias dormentes até que ocorra a manifestação, essas são encapsuladas em partículas pequenas compostas de argila expansível e lactato de cálcio. Logo, quando 
surge uma fissura, as cápsulas são rompidas e as bactérias entram em contato com a água e começam a se alimentar do cálcio que reage com o carbono e produz o calcário, que por sua vez preenche as fissuras existentes.

O uso do concreto microbial na engenharia vem se tornado cada vez mais popular. Segundo Vekarina e Pitroda (2013) suas possíveis aplicações consistem em aperfeiçoamento na durabilidade de materiais cimentícios, reparo de monumentos de calcário, vedação de fissuras em concreto e até mesmo na produção de tijolos com alta durabilidade.

$\mathrm{O}$ concreto microbial é produzido a partir de micro-organismos que sucedem naturalmente à temperatura ambiente e, dessa forma, demandam menor poder energético para sua reprodução. É importante ressaltar que os micro-organismos empregados não causam doenças patogênicas e nem são nocivos ao meio ambiente. Além disso, diferentemente do cimento, solos ou terras contaminadas podem ser tratadas ou melhoradas sem alterar o ambiente.

A aplicação de diferentes bactérias conforme alguns autores é apresentado no Quadro 1 abaixo.

Quadro 1 - Aplicação de diferentes organismos em áreas da construção.

\begin{tabular}{|c|c|c|}
\hline \multirow{2}{*}{ Aplicaçào } & Organismo & Referência \\
\hline \multirow{4}{*}{$\begin{array}{c}\text { Argamassa de cimento e } \\
\text { concreto }\end{array}$} & Bacillus cereus & Le Metayer-Leverel et al (1999) \\
\cline { 2 - 3 } & Bacillus sp. CT-5 & Achal et al, 2011 \\
\cline { 2 - 3 } & Bacillus pasteurii & Ramachandran et al (2001) \\
\cline { 2 - 3 } & Shewanella & Ghosh et al (2005) \\
\cline { 2 - 3 } Remediação de fissuras em & Sporosarcina pasteurii & Achal et al (2011) \\
\cline { 2 - 3 } concreto & Sporosarcina pasteurii & Bang et al (2001) \\
\cline { 2 - 3 } & Bacillus pasteurï & Ramachandran et al (2001) \\
\cline { 2 - 3 } & Bacillus pasteuri & Ramakrishnan (2007) \\
\cline { 2 - 3 } & Bacillus sphaericus & De Belie et al (2008) \\
\cline { 2 - 3 } & Bacillus sphaericus & D Muynck et al (2008) \\
\hline \multirow{3}{*}{ Autocicatrização } & Bacillus pseudofirmus & Jonkers et al (2007) \\
\cline { 2 - 3 } & Bacillus cohnii & Jonkers et al (2007) \\
\hline
\end{tabular}

Fonte: Vekariya e Pitroda (2013).

Partindo dos pontos positivos pertinentes ao uso do bioconcreto, destacam-se o aumento da vida útil e a viabilidade econômica. Segundo Silva e Passarini (2017), a habilidade de autorregeneração, a durabilidade e a eficiência do bioconcreto reduzem os custos de manutenção e reparos e estende a vida útil de construções, além de ser um material sustentável. Mendes et al (2016), afirmam que a utilização de bactérias dormentes na mistura do concreto, além de preencher as fissuras, aumenta o tempo de vida das estruturas e garanti condições seguras de uso, além de diminui a necessidade de realização de manutenções.

Em seus estudos, Reis (2017) analisa a durabilidade do bioconcreto a longo prazo (anos) e a eficiência de custo desse novo tipo de concreto. Segundo esse autor, os benefícios potenciais do bioconcreto são principalmente a redução de custos de manutenção e reparação, a extensão da vida útil das construções e o fato desse ser um material sustentável.

Para melhor exemplificar a durabilidade do bioconcreto a longo prazo, a Tabela 2 apresenta os resultados dos ensaios de resistência à compressão no concreto durante o período de 365 dias. 
Research, Society and Development, v. 10, n. 4, e37210414270, 2021

(CC BY 4.0) | ISSN 2525-3409 | DOI: http://dx.doi.org/10.33448/rsd-v10i4.14270

Tabela 2 - Relação de resultados de ensaio de resistência à compressão do concreto.

\begin{tabular}{ccc}
\hline Dias & $\begin{array}{c}\text { Concreto convencional } \\
\mathrm{N}^{2} \mathrm{~mm}^{2}(\mathrm{Mpa})\end{array}$ & $\begin{array}{c}\text { Bioconcreto } \\
\mathrm{N} / \mathrm{mm}^{2}(\mathrm{Mpa})\end{array}$ \\
\hline $\mathbf{7}$ & 37,57 & 39,48 \\
\hline $\mathbf{1 4}$ & 44,73 & 51,26 \\
\hline $\mathbf{2 8}$ & 51,19 & 60,17 \\
\hline $\mathbf{6 0}$ & 55,39 & 63,35 \\
\hline $\mathbf{9 0}$ & 56,97 & 66,27 \\
\hline 180 & 58,37 & 67,62 \\
\hline $\mathbf{2 7 0}$ & 59,17 & 68,84 \\
\hline 365 & 60,87 & 70,07 \\
\hline
\end{tabular}

Fonte: Silva e Passarini (2018).

De acordo com os dados é notório o acréscimo da resistência com o passar dos dias. É perceptível, em comparação ao concreto convencional, que o bioconcreto apresenta uma resistência considerável à compressão. A Figura 05 apresenta os dados da análise comparativa da resistência à compressão dos dois concretos.

Figura 5 - Analise de resistência à compressão.

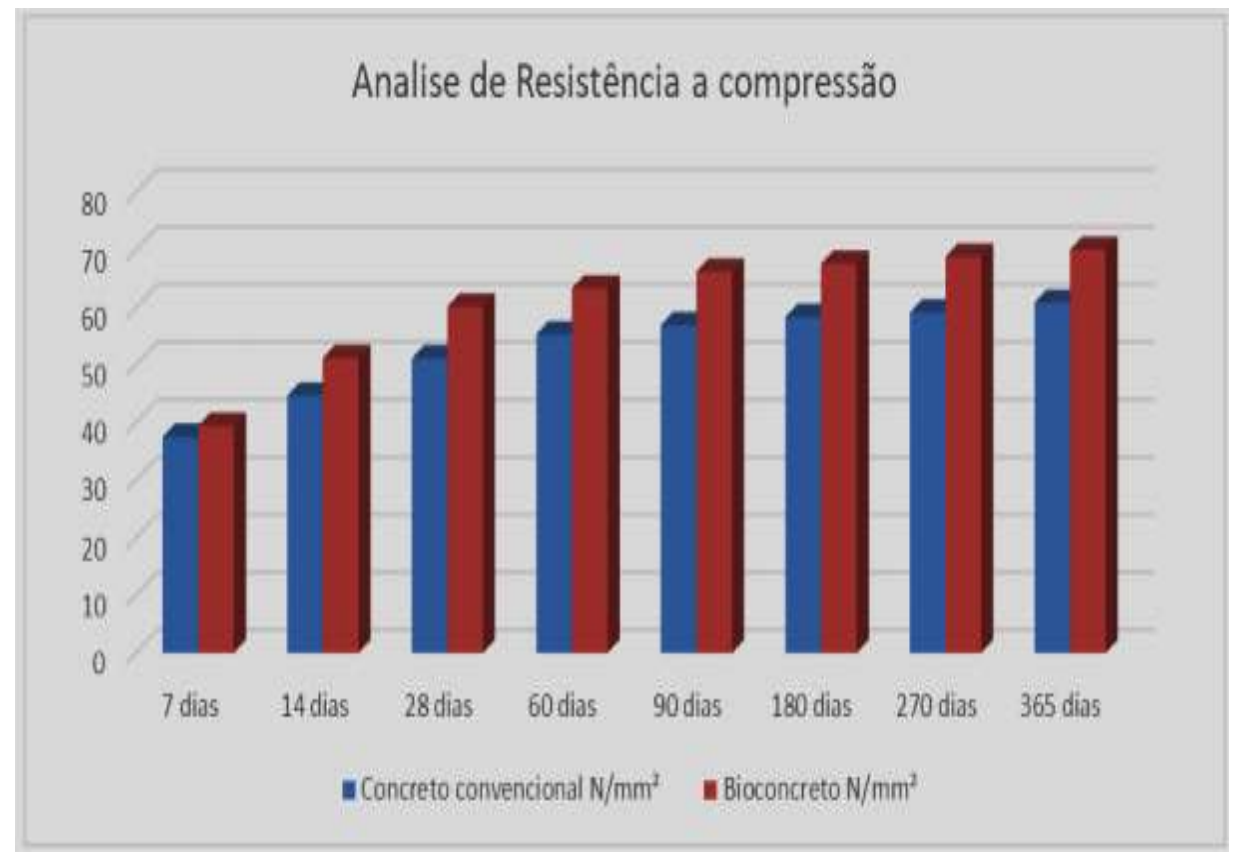

Fonte: Silva e Passarini (2018).

Analisando o teste de 365 dias, nota-se um ganho de resistência de aproximadamente $10 \%$ em comparação ao teste realizado a 7 dias, que era de aproximadamente $2 \%$. Isso se deu em virtude dos poros presentes no concreto serem preenchidos por carbonato de cálcio, que é precipitado pelas bactérias, gerando, por conseguinte, maior resistência ao concreto. 


\section{Conclusão}

O presente estudo buscou agregar com embasamento científico os benefícios da utilização do bioconcreto na construção civil. A partir deste estudo teórico observou-se que o uso do bioconcreto apresenta-se como uma alternativa altamente sustentável e promissora para a mitigação de problemas patológicos relacionados às fissuras na construção civil, além de ser uma opção para minimizar a necessidade de reparos. Observa-se também o e aumento na durabilidade dos concretos feito a partir da inserção das bactérias, visto seu ganho de resistência ao longo do tempo, apresentando desempenho superior quando comparados ao concreto comum. A partir dos dados considerados, conclui-se que o bioconcreto de fato comprova sua eficiência, sendo assim a aplicação de forma correta promissora, de modo a aperfeiçoar a capacidade de autocura do concreto. Sendo assim, o estudo e aplicação desse recurso pode simplificar alguns processos de construção, bem como revolucionar as novas formas de processos construtivos atuais e ainda promover um novo enfoque a problemática de engenharia ambiental, a partir da adoção de soluções mais sustentáveis no ramo da construção civil.

\section{Referências}

Arnold, D. (2011). Self-healing concrete. Emerging Technology, 39-43.

Azevedo, M. D (2011). Patologia das Estruturas de Cocnreto. In: ISAIA, Geraldo C. (Org.). Concreto: Ciência e Tecnologia. IBRACON, $1119-1128$.

Azevedo, M. D NBR 7211: Agregados para concreto - Especificação.

Azevedo, M. D NBR NM 248: Agregados - Determinação da composição granulométrica.

Brito, A. V. \& Nascimento, M. S. (2018). A implantação do Bioconcreto desenvolvido para solucionar problemas estruturais tais como: Fissuras, Rachaduras e Trincas. Revista Científica Semana Acadêmica. https://semanaacademica.org.br/system/files/artigos/bioconcreto-_pos_grad.1_artigo_0.pdf.

CIMENTO.ORG. Cimento Brasil. 2021. < https://cimento.org/cimento-no-brasil/>.

Cincotto, M. A. (2011). Reações de hidratação e pozolânicas. Concreto: ciência e tecnologia. IBRACON.

Gonçalves, E. A. B. (2015). Estudo de patologias e suas causas nas estruturas de concreto armado de obras de edificações. UFRJ.

Helene, P., \& Andrade, T. (2010). Concreto de Cimento Portland. In Materiais de construção civil e princípios de ciência e engenharia de materiais (p. 909).

IBGE. Instituto Brasileiro de Geografia e Estatística. Malha Federal. Downloads, 2020. https://www.ibge.gov.br/geociencias/organizacao-do-territorio/15774malhas.html?=\&t=downloads $>$.

Jonkers, H. M., Thijssen, A., Muyzer, G., Copuroglu, O., \& Schlangen, E. (2010). Application of bacteria as self-healing agent for the development of sustainable concrete. Ecological engineering, 36(2), 230-235.

Marcelli, M. (2007). Sinistros na construção civil. Pini.

Medeiros, D. P. C. (2020). Uso de bactérias (bacillus subtilis e bacillus cereus) na produção de bioconcreto. Universidade Federal da Paraíba. Curso de Engenharia Civil. João Pessoa.

Mehta, P. K., \& Monteiro, P. J. M. (2008). Concreto: microestrutura, propriedades e materiais. Ibracon.

Mendes, F. G. B., Ruas, B. L. A., Silva, R. K. R., Melo, T. M., Eleutério, I. A. R., Costa, R. A. L. Gomes. L. S. P. (2016). Concreto auto regenerativo: uma revisão bibliográfica sobre suas propriedades e benefícios para as estruturas de concreto. Anais de eventos. $10^{\circ} \mathrm{FEPEG}$. Montes Claros.

Oliveira, A.M. (2012). Fissuras e rachaduras causadas por recalque diferencial de fundações. Belo Horizonte: Monografia (Especialização em Gestão em Avaliações e perícias) - Universidade Federal de Minas Gerais.

Oliveira, T. Y. M. D. (2015). Estudo sobre o uso de materiais de construção alternativos que otimizam a sustentabilidade em edificações. Rio de Janeiro. Pinheiro. L. M., Muzardo, C. D., Santos, S. P. (2007). Fundamentos do concreto e projeto de edifícios. Universidade de São Paulo. 380 p. São Carlos.

Schneider, S.\& Schimitt, C. J. (1998). O uso do método comparativo nas Ciências Sociais. Cadernos de Sociologia, 9.

SNIC. Sindicato Nacional da Indústria de Cimento. (2021). Perfil de Consumo de 2020. http://snic.org.br/numeros-industria.php>.

Soares, A. P. F., Vasconcelos, L. T., do Nascimento, F. B. C.(2015). Corrosão Em Armaduras De Concreto. Caderno de Graduação-Ciências Exatas e Tecnológicas-UNIT-ALAGOAS, 3(1), 177-188.

Souza, V. C. M. de, \& Ripper, T. (1998). Patologia, recuperação e reforço de estruturas de concreto (PINI (ed.)). 
Research, Society and Development, v. 10, n. 4, e37210414270, 2021

(CC BY 4.0) | ISSN 2525-3409 | DOI: http://dx.doi.org/10.33448/rsd-v10i4.14270

Silva, F. P. C., de Carvalho Passarini, V., \& Santos, F. C. S. (2017). Bioconcreto: A Tecnologia Para Construção Sustentavel. INOVAE-Journal of Engineering, Architecture and Technology Innovation (ISSN 2357-7797), 5(2), 41-58.

Thorus Engenharia. Bioconcreto você sabe o que é? (2019).:< https://thorusengenharia.com.br/bioconcreto-o-que-e-concreto-regenerativo/> .

Trindade, D. S. (2015). Patologia em estruturas de concreto armado. Trabalho de Conclusão de curso. Universidade Federal de Santa Maria. 88 p.

Takagi, E. M. (2013). Concretos autocicatrizantes com cimentos brasileiros de escória de alto-forno ativados por catalisador cristalino.

Vekariya, M. S., \& Pitroda, J. Bacterial Concrete: New Era for Construction Industry.

Vekariya, M. S., \& Pitroda, J. (2013). Bacterial concrete: new era for construction industry. International journal of engineering trends and technology, 4(9), 4128-4137. 